\title{
ARDUINO BASED DIAGNOSTICS SYSTEM DEDICATED TO ROLLING BEARINGS
}

\author{
R. Kostek ${ }^{*}$
}

\begin{abstract}
This article presents: a test stand dedicated to testing rolling bearings; a low cost diagnostic system based on Arduino Mega and experimental results obtained with this system. Employed sensors were calibrated and described. Some attention was paid to measured errors. Next state indicators obtained from experimental results were presented. Provided information is useful for companies and researchers, who are focused on condition monitoring. The diagnostic system works properly and can be used in practice.
\end{abstract}

Keywords: arduino, condition, monitoring, rolling, bearing

\section{Introduction}

Rolling bearings are widely used in many machines, and thus influence their quality and reliability. Three typical signals are used to detect defects: vibrations, nose and temperature. At the beginning, amplitudes of vibrations are small, in consequence bearings run quiet. Then some faults excite vibrations, which results in larger vibration amplitude and louder noise. Finally severe faults lead to larger energy dissipation and temperature increase. These and other signals are used to detect faults. Professional equipment used in machinery diagnostics is expensive, thus small companies do not use any vibro-meter. Moreover, vibration and temperature should be monitored at many points to detect faults at an early stage. Finally, researchers rarely present results of condition monitoring. Thus, there is a need to present results of condition monitoring and a diagnostic system, which can be applied in common machines.

\section{Diagnostic system}

A diagnostic system should measure acceleration, temperature and the speed of a shaft, thus the following sensors were selected: 3-axis accelerometer ADXL335, digital thermometer DS18B20 and Hall effect sensor A3144 (Fig. 1). Accelerometers were calibrated against gravitational acceleration. The sensitivity declared by the manufacturer is in the range $270-330 \mathrm{mV} / \mathrm{g}$, whereas those measured are in the range $319-330 \mathrm{mV} / \mathrm{g}$. The bandwidth for $X_{\mathrm{OUT}}$ is from 0 to $1600 \mathrm{~Hz}$. Moreover, cross-axis sensitivity is $1 \%$ and measured noise is $0.1 \mathrm{~m} / \mathrm{s}^{2}$. On the other hand, thermometers were calibrated against temperatures $0{ }^{\circ} \mathrm{C}$ and $100{ }^{\circ} \mathrm{C}$. Errors of temperature sensors measured in $t=0{ }^{\circ} \mathrm{C}$ was in the range from 0.19 to $0.56{ }^{\circ} \mathrm{C}$, whereas the largest noise was $1 / 16^{\circ} \mathrm{C}$, which is below declared values. DS18B20 measures temperatures from $-55^{\circ} \mathrm{C}$ to $+125^{\circ} \mathrm{C}$, whereas temperatures of rolling bearings are usually in the range from $-10^{\circ} \mathrm{C}$ to $85{ }^{\circ} \mathrm{C}$.

Measured time histories should be processed, presented and saved to a file, thus the following elements were chosen: a programmable micro-controller Atmel ATmega2560, $16 \times 2$ LCD module, micro-SD card module. The Arduino Mega provides an opportunity to connect these elements in to one diagnostic system (Fig. 2). Four accelerometers measured acceleration of block housings; the sampling frequency was $8920 \mathrm{~Hz}$, thus aliasing was not observed. Four thermometers measured temperatures of the housings near to the bearings, whereas one thermometer measured the ambient temperature near the LCD. This

Robert Kostek, PhD.: University of Science and Technology in Bydgoszcz, Al. prof. S. Kaliskiego 7; 85 796, Bydgoszcz; PL, robertkostek@o2.pl 
provides an opportunity to observe any increase of the temperature of the housing and reduce low frequency noise caused by the ambient temperature. Finally, the Hall sensor provides an opportunity to measure the rotational speed of shaft (Fig. 3). Each ball bearing 608 2RS was loaded with the radial force $P=795 \mathrm{~N}$. Loading forces were measured with two force transducers HBM S9M/1KN. The shaft was driven by an asynchronous motor, with rotational speed being in the range $n \approx 2965-2980 \mathrm{rpm}$. Basic dynamic load rating for the bearing 608 is $C=3.3 \mathrm{kN}$, thus the basic rating life is $L_{10}=71.52 * 10^{6}$ revolutions. Obtained results was saved every $20 \mathrm{~s}$. Amplitudes of acceleration were calculated from time histories containing 3000 samples, whereas rotational speed was calculated from the time of four revolutions. For more information, please see https://youtu.be/Cw1bwLjB2Ow.

(a)

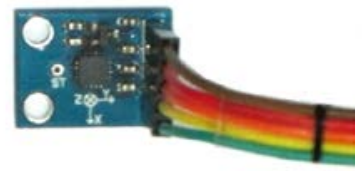

(b)

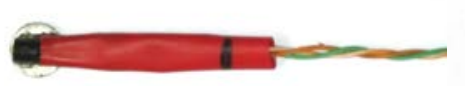

(c)

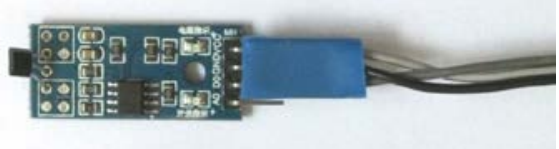

Fig. 1: Selected sensors: accelerometer ADXL335 (a), digital thermometer DS18B20 (b), and Hall effect sensor A3144 (c)

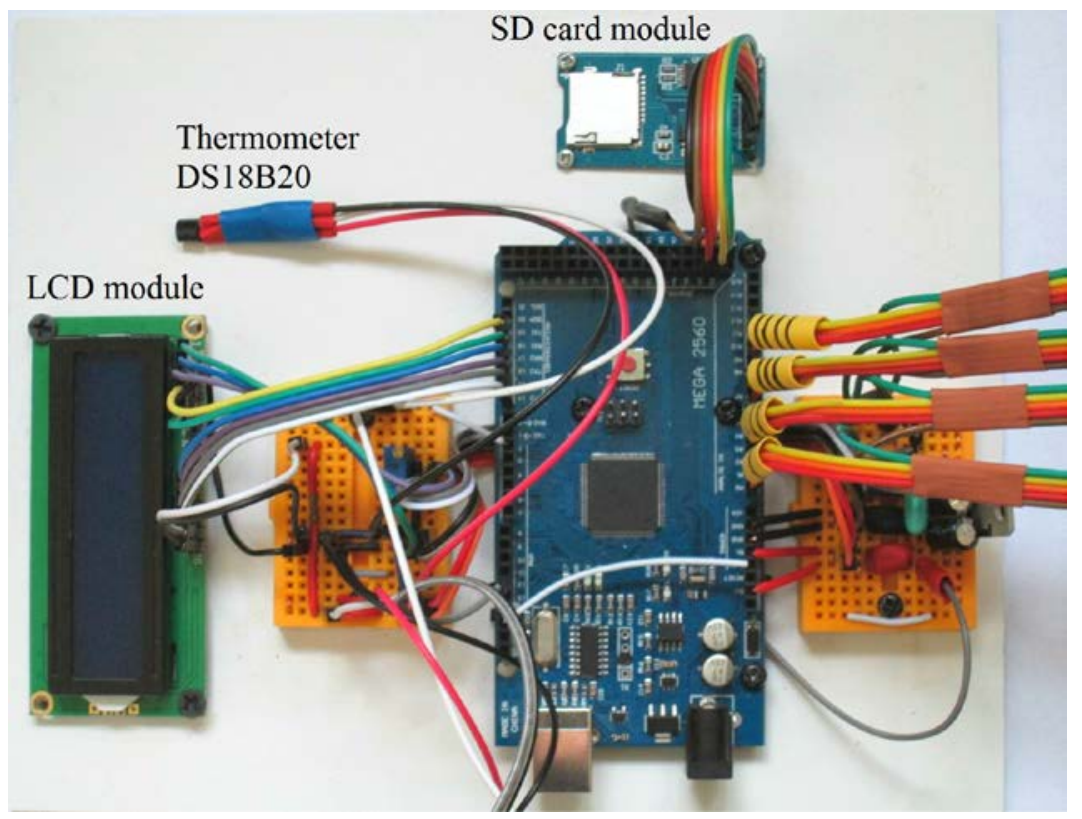

Fig. 2: Arduino mega with micro-SD card module, LCD module and thermometer

\section{Analysis of experimental results}

Presented results refer to the 1ts housing, because its bearing broke as a first. Amplitudes measured in $X$ (vertical) direction (peak to peak $A_{1 \text { xp }-\mathrm{p}}=\left(A_{1 \mathrm{xmax}}-A_{1 \mathrm{xmin}}\right) / 2$, RMS $A_{1 \mathrm{xrms}}$, average $A_{1 \text { xavg }}$ ) are depicted in Fig. 4a. Measured amplitudes are noisy, thus various magnitudes are observed within a small time interval. It is a result of various ball settings within bearings. Based on obtained results $A_{1 \times p-p}>2.5 \mathrm{~m} / \mathrm{s}^{2}$ can be proposed as an alarm level. Moving median calculated from eleven samples was used to reduce variation of amplitude (Fig. 4b). Amplitudes are on similar level up to $3.26 * 10^{6}$ revolutions, later rise up to $\operatorname{Med}_{11}\left(A_{1 \mathrm{xp}-\mathrm{p}}\right)=4.02 \mathrm{~m} / \mathrm{s}^{2}$, and next drop to $\operatorname{Med}_{11}\left(A_{1 \mathrm{xp}-\mathrm{p}}\right)=0.83 \mathrm{~m} / \mathrm{s}^{2}$, then rise one more time up to $\operatorname{Med}_{11}\left(A_{1 \times p-p}\right)=11.1 \mathrm{~m} / \mathrm{s}^{2}$. This shows, that a temporally drop of amplitude, does not means better condition. In consequence, the maximal value of $\operatorname{Med}_{11}\left(A_{1 \times p-p}\right)$ can be a state indicator. $\operatorname{Max}\left(\operatorname{Med}_{11}\left(A_{1 \text { xp }-\mathrm{p}}\right)\right)>2.6 \mathrm{~m} / \mathrm{s}^{2}$ can be an alarm level. Apart from amplitudes, coefficients $I=A_{1 \mathrm{xp}-\mathrm{p}} / A_{1 \text { xavg, }}$, $C=A_{1 \times \mathrm{p}-\mathrm{p}} / A_{1 \mathrm{xrms}}$ and $K=A_{1 \mathrm{xrms}} / A_{1 \text { xavg }}$ are used as state indicators (Fig. 4c) (Cempel, 1989). Nevertheless, theirs values are within a similar range during the experiments, and thus are not the best state indicators. The main reason is, that magnitudes of the afore-mentioned amplitudes are strongly correlated; in consequence the coefficients are not changing significantly (Fig. 4d). This was reported previously for simulation results (Kostek, 2013a; Kostek et al., 2015). In this case, application of filtration does not 
provide any more information. Moreover, for $n=0 \mathrm{rpm}$ various values of coefficients were observed, which is disadvantageous; this values are indicated with three arrows.
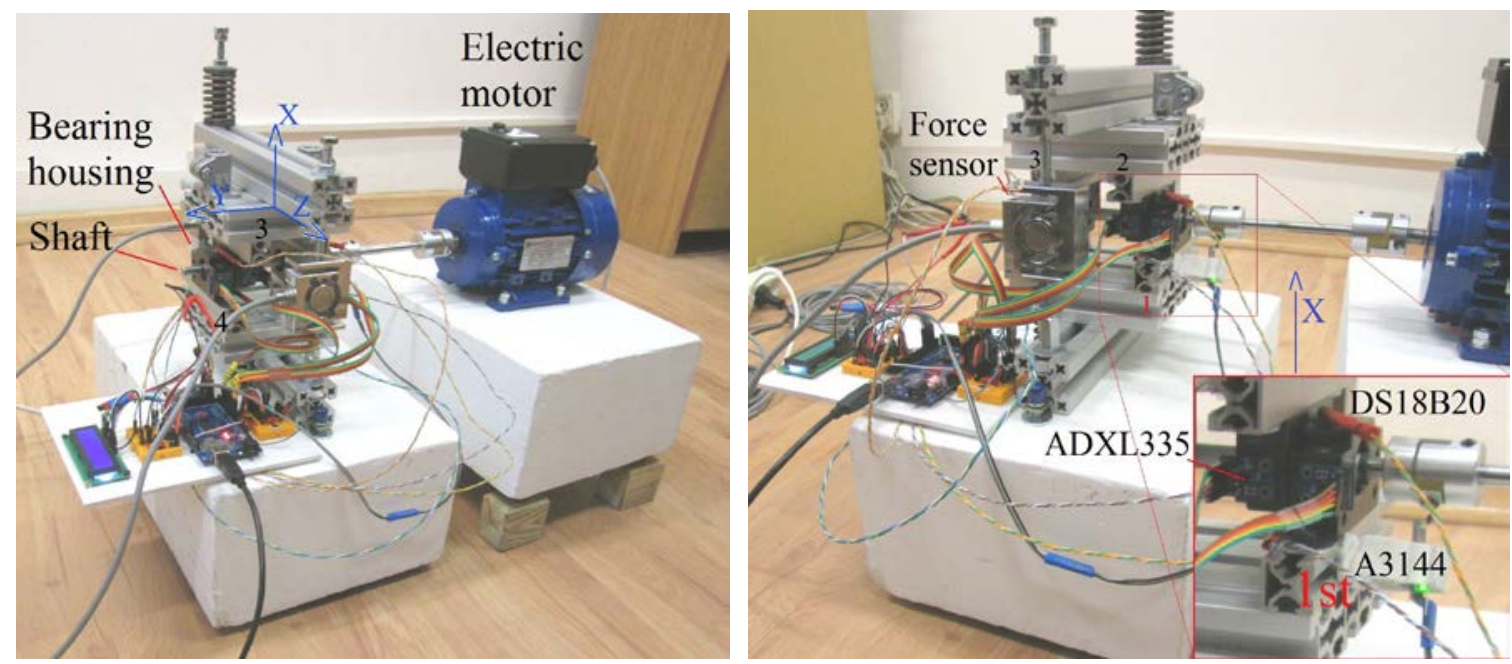

Fig. 3: General view of the test stand and the first housing
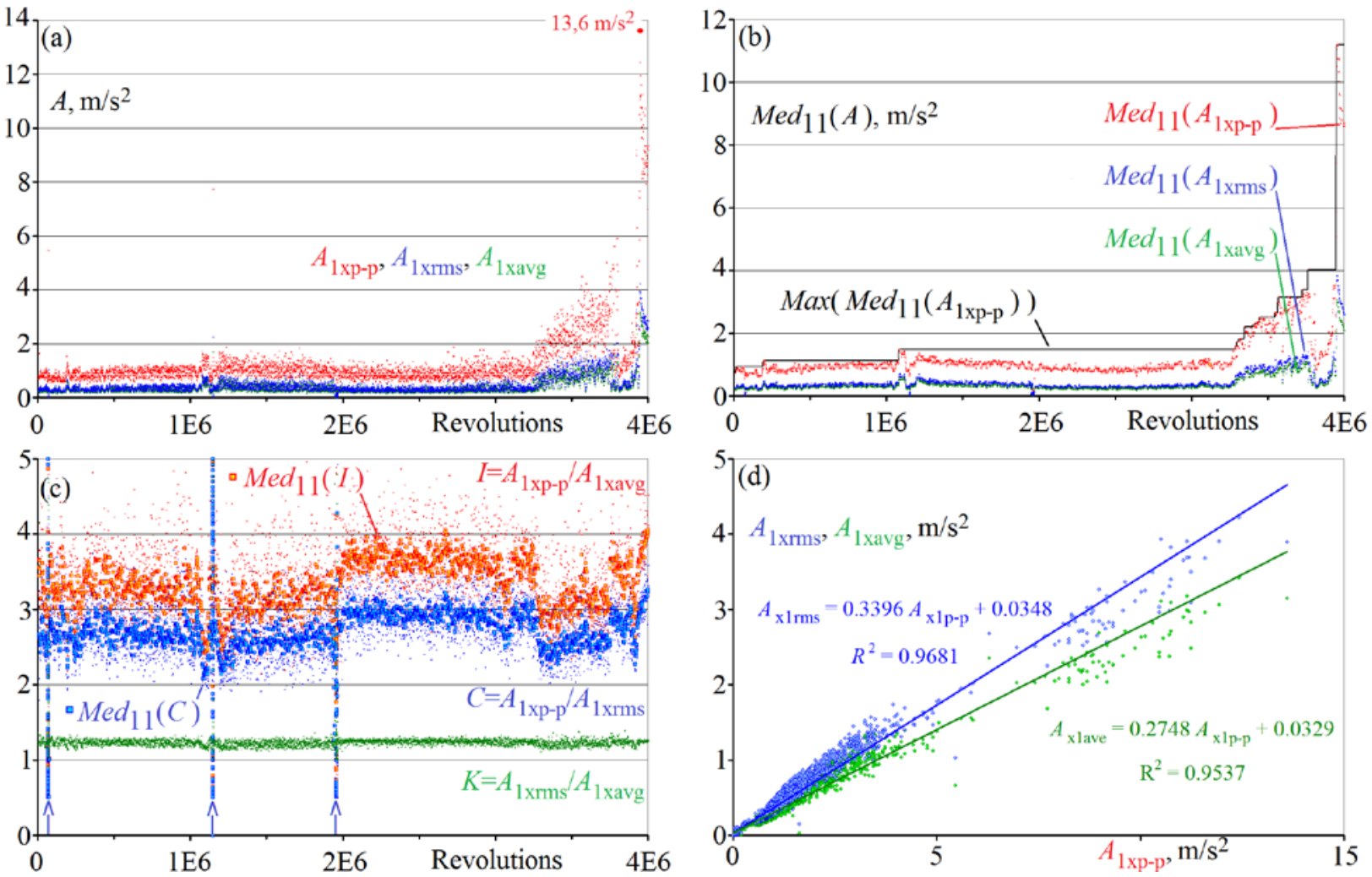

Fig. 4: Results obtained for the first housing: vibration amplitudes measured in $x$ direction versus number of revolutions (a), medians of 11 amplitudes versus number of revolutions (b), coefficients I C K and medians $\operatorname{Med}_{11}(I) \operatorname{Med}_{11}(C)$ versus number of revolutions (c), root mean square amplitude $A_{1 \mathrm{xrms}}$ and average amplitude $A_{1 \text { ang }}$ versus peak to peak amplitude $A_{1 \times p-p}(d)$

Ambient temperature $t_{0}$ was not constant during the experiment, thus it should be measured (Fig. 5a). It introduces low frequency noise, which is difficult to reduce. Temperature of the 1ts housing was rising shortly after the start, and then stabilised near $t_{1} \approx 34{ }^{\circ} \mathrm{C}$. This temperature dropped three times, because the engine was stopped three times. For number of revolutions being $3.84 * 10^{6} t_{1}$ dropped to $32.5{ }^{\circ} \mathrm{C}$ and next reached $100.1{ }^{\circ} \mathrm{C}$. This is a result of larger friction moment and shows degradation of the bearing and its lubricant. Lubricant was partially removed from this bearing during the test. The increase of $\Delta t=t_{1}-t_{0}$ is a useful state indicator, which reflects power dissipation. $\Delta \mathrm{t}>15$ can be an alarm level. Presented system provides an opportunity to observe time histories of temperatures. Housing temperature 
rises after start-up, and then stabilises $\Delta t=9.35{ }^{\circ} \mathrm{C}$ above the ambient temperature (Fig. 5c). The parameters of the first order system were identified from experimental results. Comparison experimental and computational results leads to conclusion, that temperature increase can be modelled with the first order system. The thermogram obtained for $4^{\text {th }}$ bearing shows that temperature of bearing is around 18.9 ${ }^{\circ} \mathrm{C}$ larger, than temperature of DS18B20 sensor. Moreover results obtained with thermography and sensors DS18B20 show good agreement.

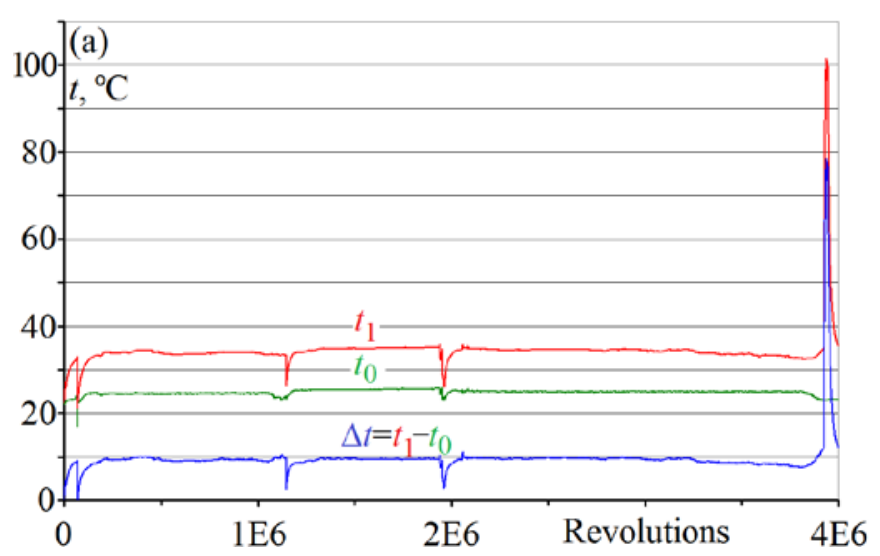

(b)
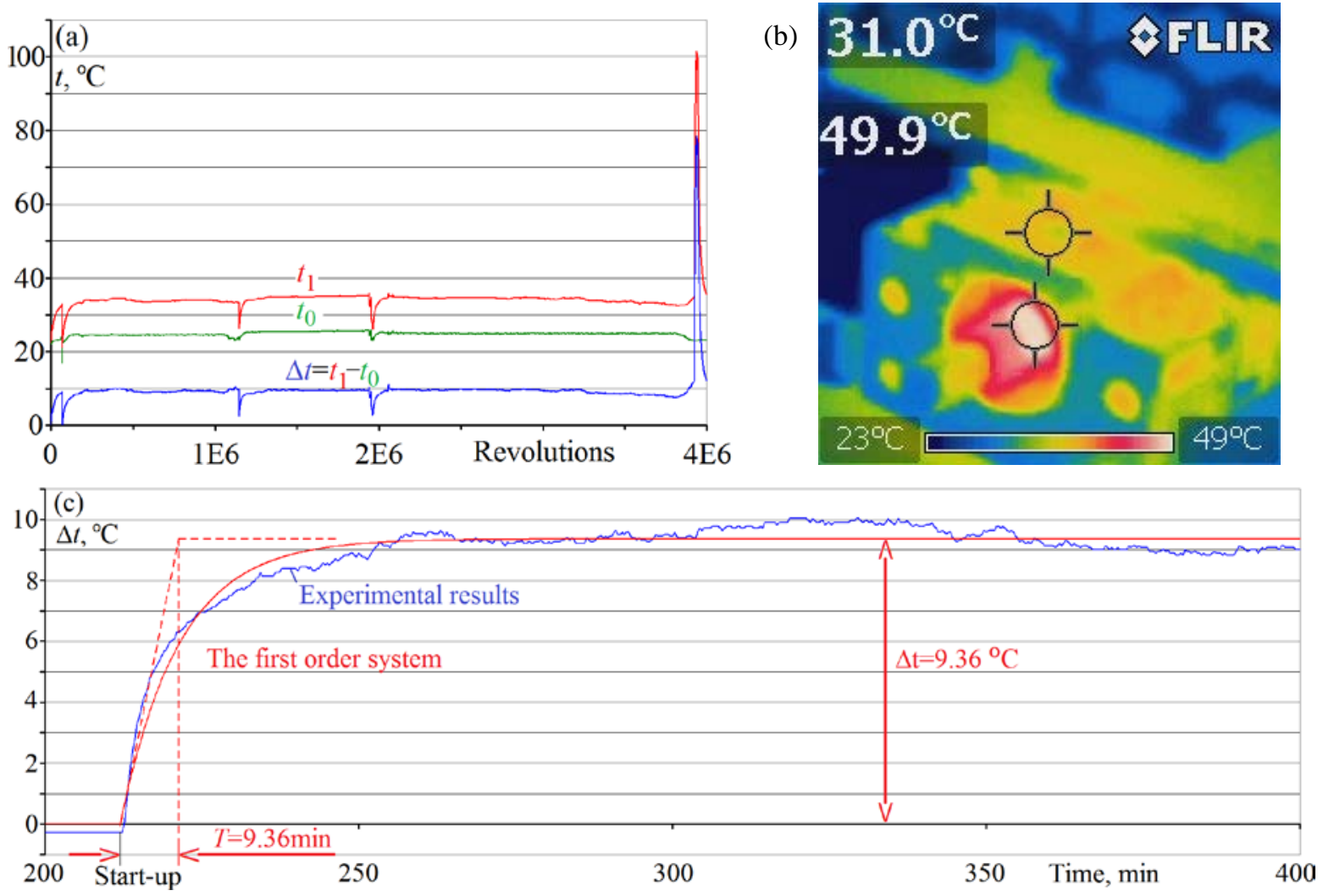

Fig. 5: Ambient temperature $t_{0}$ and temperature of the 1ts housing $t_{1}$ versus number of revolutions (a), time history of $\Delta t$ measured for the 1ts housing (c), thermogram of 4th housing obtained with Flir i5 (b),

\section{Conclusions}

Contact between bodies and friction, influence the dynamics of bearing, thus this issue is coupled with machinery diagnostics (Kostek, 2013b). Researchers tend to use expensive sensors and programs, but in practice diagnostic systems can contain low cost sensors and micro-controllers (Lukasiewicz et al., 2014). Presented diagnostic system works and can be used by small companies in many machines. This system is able to provide valuable information, for example: noisy amplitudes were observed, and time histories of temperatures after start-up. Moreover, a number of failure modes were presented: median of amplitude, and $\Delta t$. At the same time coefficients $I C$ and $K$ were not good state indicators. Obtained results are promising, thus studies will be continued.

\section{References}

Cempel C. (1989) Vibro-acoustic Diagnostics of Machinery. PWN, Warsaw

Kostek R. (2013a) Direct numerical methods dedicated to second-order ordinary differential equations. Applied Mathematics and Computation, 219.19, pp.10082-10095

Kostek R. (2013b) Analysis of the primary and super-harmonic contact resonances - Part 1. Journal of Theoretical and Applied Mechanics, 51.2, pp.475-486

Kostek R., Landowski B. and Muślewski Ł. (2015) Simulation of rolling bearing vibration in diagnostics. Journal of Vibroengineering, 17.8, pp.4268-4278

Łukasiewicz M., Kałaczyński T., Musiał J. and Shalapko J.I., (2014) Diagnostics of buggy vehicle transmission gearbox technical state based on modal vibrations. Journal of Vibroengineering 16.6, pp. 3137-3145 